Review article

\title{
The factors affecting the obstetricians-gynecologists workforce planning: A systematic review
}

\author{
Roghayeh Khalilnezhad ${ }^{\mathrm{a}, \mathrm{b}}$, Hasan Abolghasem Gorji ${ }^{\mathrm{b}, *}$, Farshid Alaedini ${ }^{\mathrm{c}}$, Ali Safavi Naeini ${ }^{\mathrm{d}}$, \\ Mohammad Mehdi Sepehri ${ }^{\mathrm{e}}$ \\ a Department of Health Services Management, School of Health Management and Information Sciences, Iran University of Medical Sciences, Tehran, Iran \\ ${ }^{\mathrm{b}}$ Health Management and Economics Research Center, Iran University of Medical Sciences, Tehran, Iran \\ c Islamic Republic of Iran Academy of Medical Sciences, Tehran, Iran \\ ${ }^{\mathrm{d}}$ Tracheal Research Center (TRC), National Research Institute of Tuberculosis and Lung Disease (NRITLD), Shahid Beshti University of Medical Sciences, Tehran, Iran \\ ${ }^{\mathrm{e}}$ Industrial and Systems Engineering, Tarbiat Modares University, Tehran, Iran
}

\section{A R T I C L E I N F O}

\section{Keywords:}

Obstetricians and gynecologists

Workforce planning

Health services needs and demand

Systematic review

\begin{abstract}
A B S T R A C T
Objectives: The purpose of this study was to investigate the models and tools used for the obstetrician-gynecologists (OB-GYNs) workforce planning and to determine the factors affecting their supply and demand.

Methods: This systematic review was conducted by searching the relevant papers published in reputable electronic databases such as PubMed, Scopus and gray literature from 1980 to 2019. PRISMA model was employed to select the papers. The data were extracted by an author-made form and analyzed using framework content analysis method.

Results: Considering the inclusion and exclusion criteria, a total of 45 papers were selected. A variety of factors and models were employed in the reviewed papers for the OB-GYNs workforce planning. The extracted data were classified under three categories: models, supply factors, and demand factors.

Conclusion: The reviewed papers had made more accurate estimates through various variables, scenarios and different mathematical and simulation models. Therefore, the human resources for health (HRH) planners are recommended to consider all effective factors in order to improve the quality of future workforce estimations.
\end{abstract}

\section{Introduction}

Human resources planning (HRP) is not a new area of research in medical sciences. In response to the needs of society and the health system, most countries constantly make various decisions to reduce or increase the number of workforces in these fields. ${ }^{1}$ Among the medical specialties, obstetrics and gynecology are under the spotlight of workforce planning due to their higher contribution than other specialties and their substantial effects on the promotion of maternal and child health. ${ }^{2,3}$ In addition, the fertility and population growth, the changing population pyramid, and the increasing need of elderly women for the OB-GYNs services necessitate reviewing OB-GYNs training policies to cover these expanded services. ${ }^{4}$ Besides the demands, OB-GYNs workforce planning should also take into account the factors that determine the number of active OB-GYNs and their supply. Physicians' job satisfaction and their efforts to maintain a work-life balance greatly affect their working hours, early retirement patterns or their tendency to work flexibly and part-time.,

As in the other medical specialties, there is no complete and reliable basis for policymakers for the OB-GYNs workforce planning. ${ }^{1,7,8}$ Therefore, it is necessary to conduct a systematic review and synthesis of the literature to ensure OB-GYNs services access. Although several review studies have been carried out about physicians, ${ }^{9-11}$ the specific characteristics of each specialty and differences between the factors influencing the definition of the needs and demand in each specialty justify the significance of a narrower review on OB-GYNs. The present study hence aims to investigate factors affecting the supply and demand of OB-GYNs through a systematic literature review.

\section{Methods}

To identify the variables for estimating the number of OB-GYNs, a systematic review study was conducted using the PRISMA (Preferred Reporting Items for Systematic Reviews and Meta-Analyses) Statement. ${ }^{12}$

\footnotetext{
* Corresponding author School of Health Management and Information Sciences, Rashid Yasami St, after Vanak square, Valiasr St, Tehran, Iran.

E-mail addresses: khalilnezhad.r@iums.ac.ir (R. Khalilnezhad), gorji.h@iums.ac.ir (H.A. Gorji), falaedini@yahoo.com (F. Alaedini), alisafavi2000@gmail.com (A.S. Naeini), mehdi.sepehri@modares.ac.ir (M.M. Sepehri).
} 


\subsection{Search strategy}

The scope of the literature review was defined based on the PICO format (Population, Intervention, Comparator, Outcomes). In this study, the population included the OB-GYNs, the intervention was defined as the type of workforce planning model and the factors mentioned important or used for determining the supply and demand of OBGYNs, and the outcomes were defined as the OB-GYNs requirement. It was not possible to outline the comparator for this review study. All papers related to the subject were searched on English databases, including Clinical Key, CRD, Embassy, PubMed, Scopus, Web of Science, Cochrane Library, and Google Scholar Search Engine, and Farsi databases, including IranMedex, Iran-Doc, and Magiran. For gray literature, theses, the websites of health ministries, international organizations such as World Health Organization and World Bank, OECD and OBGYNs societies, associations, committees, and documents published by them were reviewed. Finally, a cited reference was done to complete the searches.

The search strategy was designed based on Medical Subjects Headings (MeSH) that uses search terms for the review of human resources for health (HRH) in previous systematic literature reviews and articles. The search terms used in this study included "physician", "specialist physician", "specialist", "medical specialist", "medical workforce", "medical manpower", "obstetrics", "gynecology", "obstetricians", "gynecologists", "OB-GYNs workforce planning", "need", "demand", "requirement", "supply", “estimation", "forecasting", "modeling", "predictions", and "calculating". The search period was from 1980 to 2019 (Fig. 1).

\subsection{Inclusion and exclusion criteria}

This review covered all published or unpublished descriptive, qualitative, and quantitative studies as original articles, reviews or theses on theoretical or practical estimation models for OB-GYNs or the factors associated with their supply and demand. Because of the capabilities and constraints of resources, only English and Farsi papers were selected for further analysis.

The selected studies could discuss or estimate OB-GYNs requirement individually or alongside that of other specialties or other related medical fields, such as maternity care. However, having specific figures and analyses on OB-GYNs was the main inclusion criterion.

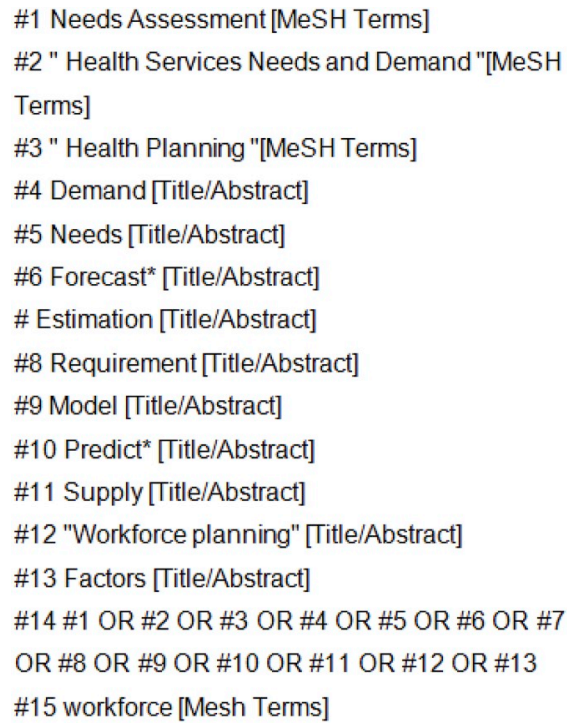

\subsection{Study selection}

References and abstracts of searched papers were inserted into a reference management software application named Endnote V.X7. After removing the duplications, two independent researchers reviewed the papers in terms of title and abstract. The papers that met the inclusion criteria were selected for the full-text analysis phase. For the gray literature, the papers were screened during the manual search and the related items were inserted into the reference management system and merged with papers selected through electronic searches. Final papers were selected based on the full-text reviews. If there was a disagreement between the researchers, it was addressed by using reconciliation proofs between the two researchers and conciliation with the third co-author used.

\subsection{Quality appraisal}

The Critical Appraisal Skills Programme (CASP) was employed to critically appraise the quality of the papers. This tool consists of 10 items in three subscales of internal validity, results, and relevance to practice. All included studies were critically appraised by this tool. ${ }^{13}$

\subsection{Data extraction}

For data extraction, a special form was designed in Excel that included the subheadings such as author, year, goal, country, target group, level of estimation (national or regional), analysis time frame, estimation focus (supply, demand or integrated (both-side)), approach/ model, and operational or mathematical method. In addition, this form involved the factors related to demand/need and supply of OB-GYNs, type of approach and model, assumptions, and scenarios.

\subsection{Data analysis}

The data were analyzed based on the deductive approach and the content analysis framework. Masnick and McDonnell model was used as basic conceptual framework for analysis. This framework included three basic components-the population to be served, the clinical workforce to serve it, and the workload of the related clinical workforce. The model links clinical workforce skill mix planning to health and health care dynamics. ${ }^{14}$ The papers were labeled and coded using the existing categories and codes of the conceptual framework. Moreover, new codes were added to the basic framework. After generating

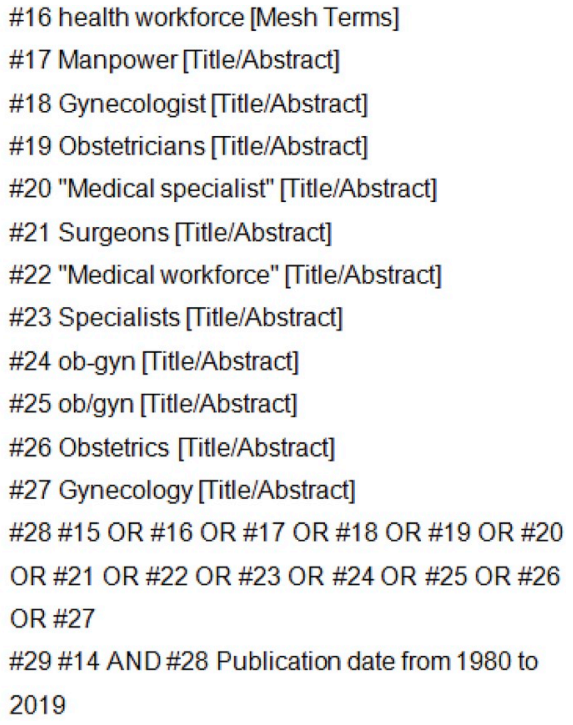

Fig. 1. Search strategy in PubMed. 


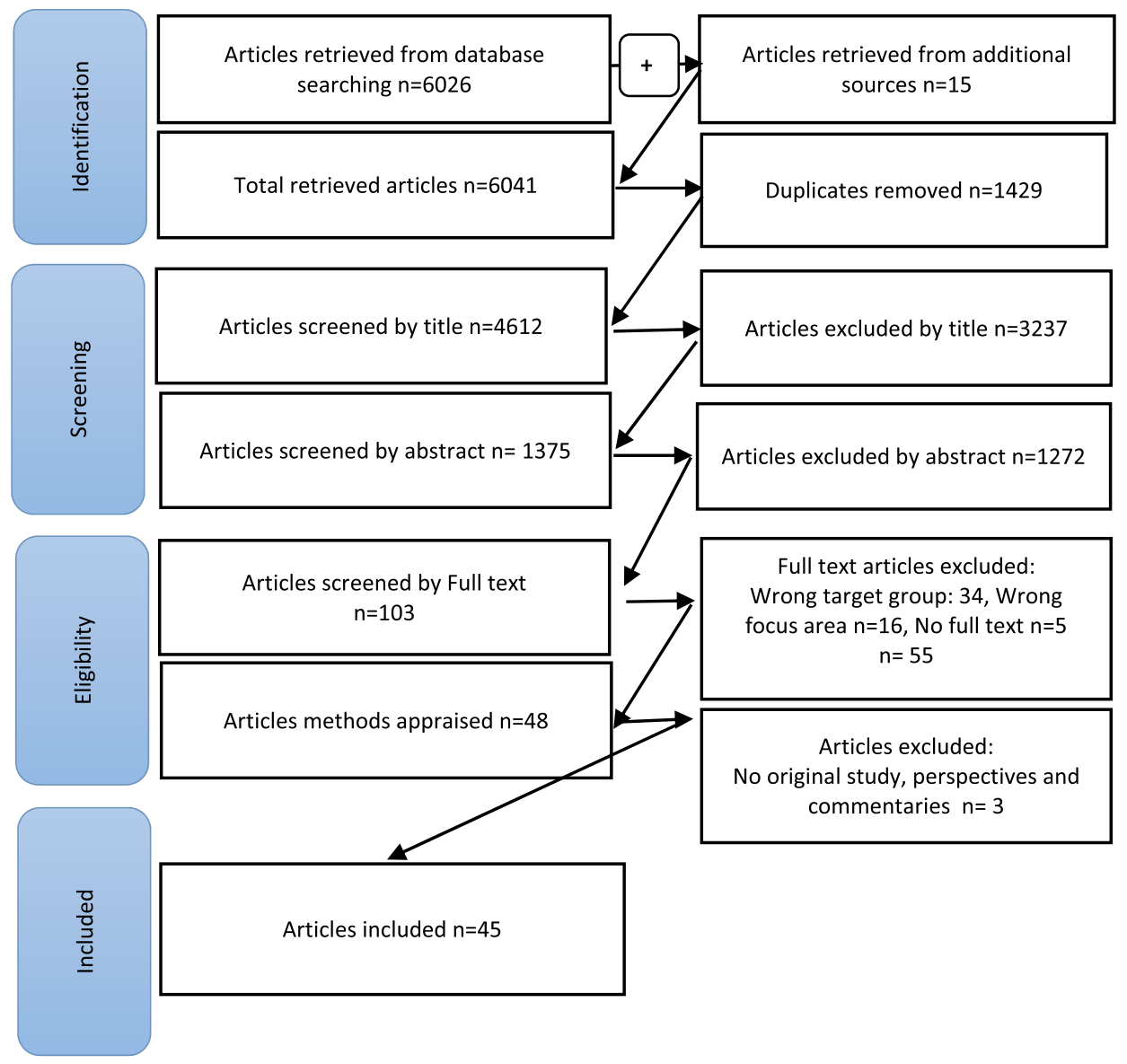

Fig. 2. Flow of screening and selecting studies (PRISMA Flowchart).

the codes, the data were charted into the matrix. The matrix involved a summary of data with codes and categories from each paper in the spreadsheet form.

\section{Results}

In this study, a total of 6026 papers were collected based on manual searches and databases. After screening the papers and applying the inclusion and exclusion criteria, 45 papers were selected for systematic review (Fig. 2). General descriptions of the included papers are presented in Table 1.

Of all selected papers, 22 were from the US, ${ }^{17,24,25,27,28,31-33,36,38,39,43-46,49,51,54-56,58,59} 5$ from Canada, ${ }^{30,40,52,}$ ${ }^{53,57} 4$ from Australia, ${ }^{18,19,26,34} 3$ from UK, ${ }^{22,23,48}$ and 10 from Ireland, Japan, Mexico, Oman, Italy, and Iran. ${ }^{15,16,20,21,29,35,37,41,42,47,50}$ A quantitative model had been used in 40 papers to estimate the OB-GYNs requirement, and 5 papers had qualitatively or descriptively investigated the factors affecting the supply and demand of the workforce in this field. The results showed that 28 and 12 papers were related to national and regional studies, respectively. Papers on HRP had focused on demand, supply or both in their estimations and discussions. According to the results, 31,10 , and 4 of the selected papers had focused on both supply and demand, just supply, and only demand, respectively. In terms of the approach used to the planning and estimation of OB-GYNs, four of the approaches employed in the selected papers are worth mentioning. Most of the papers focused on the supply side used the Stoke and Flow model, and the trend analysis method was observed in only two papers. ${ }^{33,35}$ At demand side, 5 papers employed need-based, ${ }^{20,23,30,42,52} 19$ papers used utilization-based or service-target ${ }^{15}, 16,19,24-27,32,34,40-41,44,46,50-51$, 55-58, and 6 papers employed adjusted need-based (needs adjusted by utilization or other factors affecting demand $)^{18,22,33,39,48,53}$ models. One of the criteria for evaluating the quality of estimates was calculating the requirement in the baseline year and then estimating requirement for the given years. ${ }^{12}$ In this respect, 11 papers had measured the baseline need and 3 papers had used proxies such as waiting times, vacant positions, specialists to population for unmet need or demand, and determined sufficiency of OB-GYNs. ${ }^{19,34,40}$ In addition, 24 papers had used different

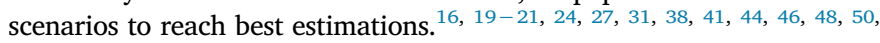
$55-57$

\subsection{The factors affecting need/demand of $O B-G Y N s$}

Based on the results of the analysis of the factors affecting the demand side in the OB-GYNs workforce planning, 35 factors in 6 categories were extracted. These 6 categories included the demographic status and predicted population growth, women's health status variables, socioeconomic factors affecting health, socioeconomic factors affecting service utilization, parameters of utilization rate, and the service system capacity and service delivery models affecting the workforce requirement. Table 2 clearly identifies the factors highlighted in each of the papers focused on the demand side.

As shown in Table 2, demographic variables including the number, age, and geographical location of women, geographical distribution (urban or rural) of female population, and population growth rate were used in almost all studies to calculate the number of specialists needed.

Variables of women's health status included factors such as birth rate, primiparity rate, mean gestational age, fertility and infertility rate, unwanted pregnancies rate (taking into account the long-term effects of non-invasive contraceptive methods), rate of the medical and surgical complications related to pregnancy, high risk pregnancies, incidence and prevalence of breast and reproductive cancers in women, prevalence of other gynecological diseases (amenorrhea and 


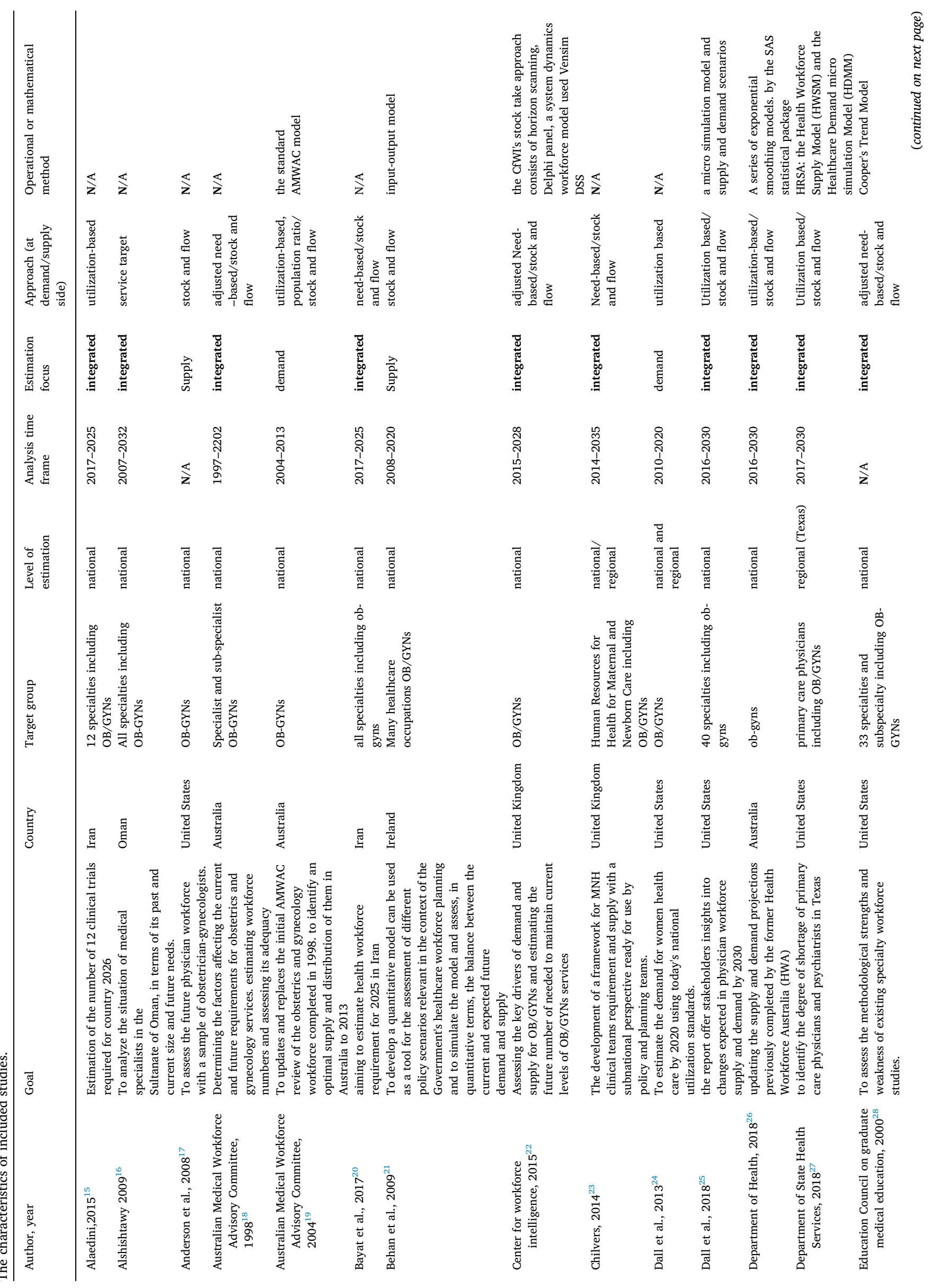




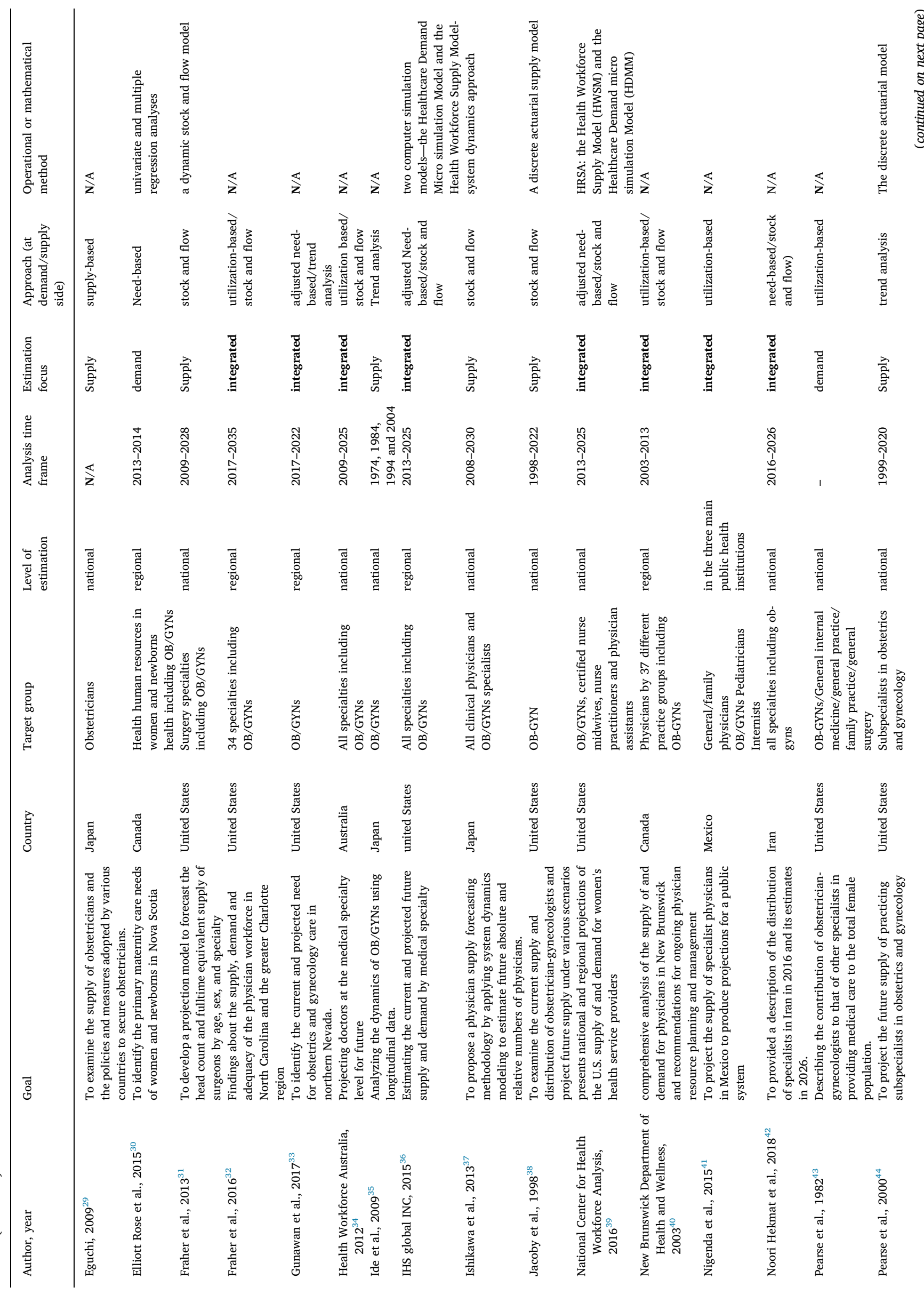




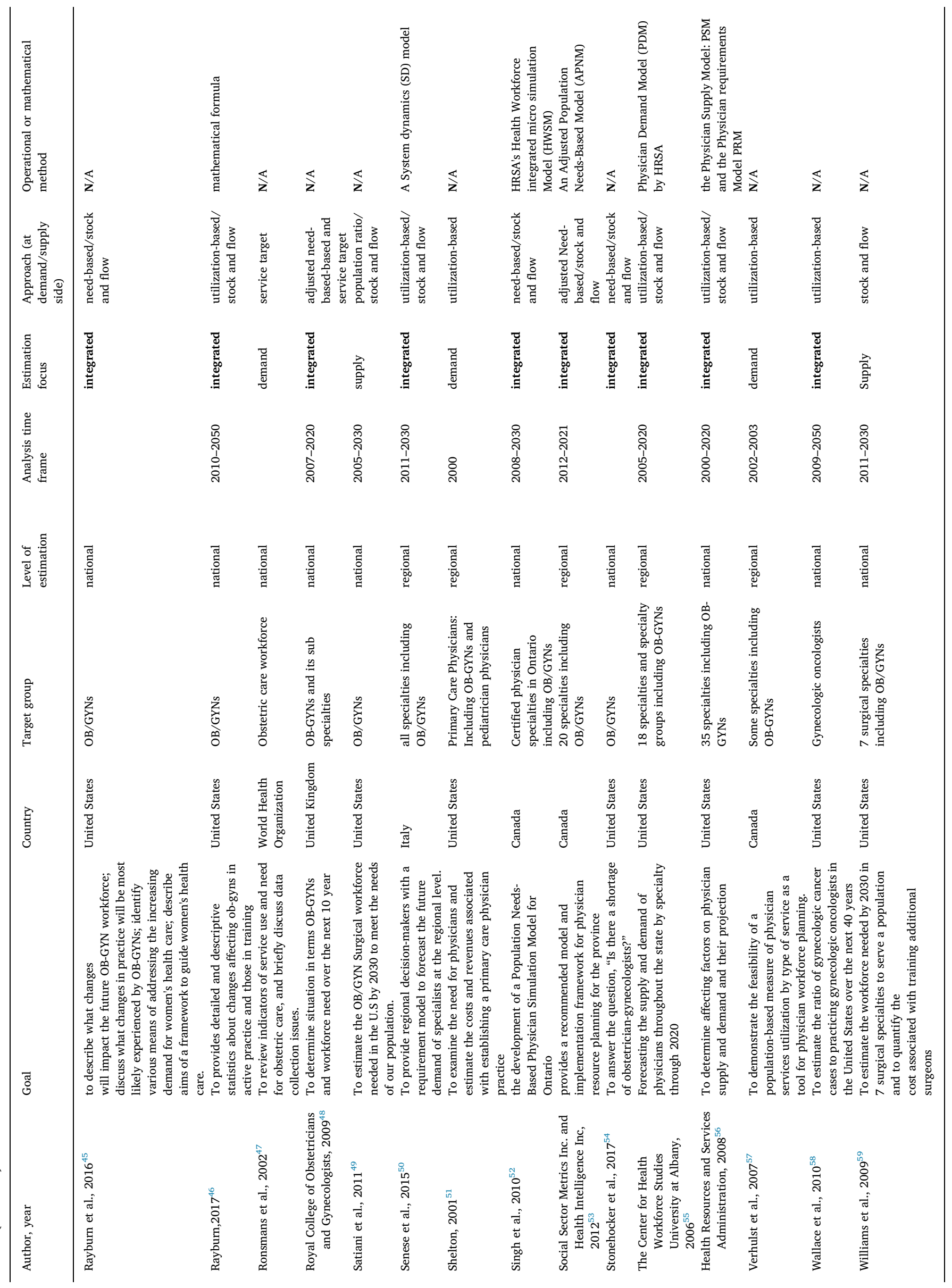


Table 2

Affecting factors on the need/demand of OB-GYNs based on the analysis of included studies.

\begin{tabular}{|c|c|c|}
\hline Factors & & Studies discussed the factor \\
\hline \multirow[t]{3}{*}{ population Demographic status } & Population of women by age group & $15,17-30,32-34,36-59$ \\
\hline & Geographical distribution of women & $22,24,30,46$ \\
\hline & Population growth, aging & $15,19,20,22,25,26,28,32-34,39,40,42,45-48,52-58,59$ \\
\hline \multirow[t]{11}{*}{ women's health status variables } & Birth rate & $18,19,22,23,28,39,46-48,54$ \\
\hline & First time pregnancy rate & 18,48 \\
\hline & Average gestational age & 22 \\
\hline & Fertility rate & $18,19,22,46$ \\
\hline & Infertility rate & $22,26,48$ \\
\hline & The rate of unwanted pregnancies & 46 \\
\hline & The rate of medical and surgical complications of pregnancy & 22 \\
\hline & High-risk pregnancies & $19,22,46,47$ \\
\hline & Incidence and prevalence of breast and reproductive cancers in women & $18-20,22,24,30,33,40,46,48,52,53,58$ \\
\hline & Prevalence of other gynecological diseases & $20,22,24,28,30,40,46,48,52,53$ \\
\hline & Mortality Rates of Pregnancy and Gynecological Diseases & $22,23,33,47,58$ \\
\hline \multirow[t]{3}{*}{ socioeconomic factors affecting health } & $\begin{array}{l}\text { Prevalence of risk factors in pregnancy and diseases related to women (such as lifestyle, } \\
\text { smoking, obesity, etc.) }\end{array}$ & $19,22-25,27,30,32,36,46,47,52,54,58$ \\
\hline & Women's literacy level & $18,24,27,28,30,33,34,46$ \\
\hline & Household income level & $23,24,27,28,30,32-34,46,52,54$ \\
\hline \multirow{3}{*}{$\begin{array}{l}\text { socioeconomic factors affecting utilization } \\
\text { of services }\end{array}$} & The amount and type of women's insurance coverage (affecting economic access) & $23-26,28,32,33,39,46,54-56$ \\
\hline & $\begin{array}{l}\text { Changing the level of women's expectations and expectations of women's health } \\
\text { services }\end{array}$ & $18,22,28,29,34,40,45,46,53$ \\
\hline & Geographical accessibility to outpatient and inpatient centers & $23,28,30,46,52,55,56$ \\
\hline \multirow[t]{7}{*}{ utilization rate parameters } & Average waiting time for outpatient and inpatient services & $18,19,28,46,48,52$ \\
\hline & Outpatient visits to gynecologists & $15,19,20,22-27,32,33,36,40-43,46,48,50,51,53,55-57$ \\
\hline & Per capita hospitalized services related to gynecology & $15,18,20,22,24-27,32-34,36,40,43,46,48,50,53,55-57$ \\
\hline & The number of pregnancies by method and place of delivery & $19,23,26,29,33,47,48$ \\
\hline & Place of delivery with service & 22,29,36,47, \\
\hline & Number of surgeries & 15,56 \\
\hline & visit times & 46,52 \\
\hline \multirow[t]{3}{*}{ Service system capacity } & $\begin{array}{l}\text { Structural capacity and availability of facilities and equipment to provide services to } \\
\text { gynecologists }\end{array}$ & 22,46 \\
\hline & The Growth and Advancement of Technologies Related to Women's Health Services & $18,22,28,40,45,46,52,54$ \\
\hline & GDP and overall growth of the economy & $18,20,28,34,39,40,46,55,56$ \\
\hline \multirow[t]{4}{*}{ service delivery models } & $\begin{array}{l}\text { Guidelines and guidelines and standards of care (affecting services needed such as } \\
\text { screening and periodic testing of non-pregnant women) }\end{array}$ & $22,23,26,28,34,40,46,50,52-54$ \\
\hline & prevention and public health measures & 45,46, \\
\hline & Payment reform/system reforms/regulations and policies & $24,26,28,32,34,39,45,46$ \\
\hline & efficiency of services & 45,46 \\
\hline
\end{tabular}

dysmenorrhea, endometriosis, fibroids, reproductive tract infections, and urinary incontinence), rate of pregnancy-related mortality, and gynecological diseases.

Socioeconomic factors such as the prevalence of risk factors for pregnancy-related and gynecological diseases (such as lifestyle, smoking, obesity, etc.), women's literacy level, and household income were mentioned in the reviewed papers. In addition, some of the reviewed papers measured socioeconomic factors affecting the utilization of women's health services, such as the extent and type of women's insurance coverage, changing women's expectations of health services, and geographic access to health centers.

The most important factors estimated in utilization-based papers were the number and rate of outpatient and inpatient visits. Some studies also measured the extent of utilization with greater depth and accuracy by examining factors such as average waiting time for outpatient and inpatient services, average time per visit, rate of different delivery methods, and the number of gynecological surgeries.

The rate of growth and development of technologies related to women's health services, economic growth, and the guidelines defining the models of service delivery and care standards such as required screening and periodic testing for pregnant or non-pregnant women were among the main factors employed in some of the reviewed papers as the model parameters, assumptions or scenarios for estimations.

In addition to all the factors mentioned above, there were a number of factors that determine the standards and capacity of the health system to provide services and thus affect the demand for services of OB-GYNs. These factors included the structural and equipment capacity of health facilities and their geographical availability to deliver OBGYNs services.

\subsection{The factors affecting the supply of OB-GYNs}

The 34 factors associated with the supply of OB-GYNs were classified under 9 categories. Table 3 shows the frequency of factors in each paper separately. In most papers that focused on the supply side, the number of active OB-GYNs determined using different data sources and registries. One of the important reasons for the shortage of professionals was their uneven distribution across different regions of a country as well as gender. The proportion of women participating in obstetrics and gynecology has increased. Moreover, given that women work less than men, these rates should be taken into account in estimating the number of available OB-GYNs. ${ }^{17,21,23,29,31,37,42,44,56}$ In the calculation of the net flow, the inflow was deceased by outflow. The factors used in the reviewed papers also included the retirement age of OB-GYNs, mortality, exit from the field, immigration rate, the number of OB-GYN residents, and annual graduation rate. The growth of OB-GYN graduates' participating in specialized fields was the main trend affecting the number of available OB-GYNs. ${ }^{17,21,22,30,39,40,47,50}$

One of the important factors in evaluating the supply of OB-GYNs was the participation and contribution of other physicians in providing specialized services in this field. ${ }^{60}$ According to the results, maternity services provided by OB-GYNs interference and overlap by primary care physicians, general practitioners, internal medicine and urology specialists. In addition, gynecological services, are also provided by general surgeons. Furthermore, considering the roles of midwives and nurses, many pregnancy services are provided by these individuals. Of course, these factors are difficult to measure and most studies have addressed them as hypotheses and scenarios. ${ }^{19,22,23,29,30,36,45,47,48,53,54}$

Working hours of OB-GYNs or their time allocation between clinical, 
Table 3

Affecting factors on the supply of OB-GYNs based on the analysis of included studies.

\begin{tabular}{|c|c|c|}
\hline Factors & & Studies discussed the factor \\
\hline \multirow[t]{3}{*}{ available ob-Gyns } & Number of Ob-Gyns in practice & $15,16,18-40,42,46,48-59$ \\
\hline & Geographical distribution of Ob-Gyns & $18,20,25,26,28-30,33,35,40,42,45,46,53,54$ \\
\hline & Demographic status of ob-Gyns (age and sex distribution) & $18-23,25-31,34-36,38-40,45,46,48,50,53-56,59$ \\
\hline \multirow[t]{4}{*}{ Out flow of the workforce } & Aging and retirement age of Ob-Gyns & $15,17-40,45,46,48-50,52-56,58,59$ \\
\hline & Mortality rate of Ob-Gyns & $20,21,23,25-28,30,31,34,37-40,48,55,56,59$ \\
\hline & Departure rates for gynecologists & $15,20,21,23,25-31,34,35,37,39,40,48,50,52,53,55,56$ \\
\hline & Migration rate & $19-23,26,30,32,34,36,39,48,52,53,55$ \\
\hline \multirow[t]{2}{*}{ workforce inflow } & Specialist Returns & $20-23,45$ \\
\hline & immigration rate & $19-23,26,30,32,34,36,39,48,52,53,55$ \\
\hline \multirow[t]{6}{*}{ residency inflow } & The number of Ob-Gyns specialty resident & $18,20,23,25-28,30,31,34,40,44,48-50,52,55,56$ \\
\hline & The number of Ob-Gyns specialty graduates & $19-21,23,25,27,28,30-32,34-36,38,40,45,46,48-50,52,54,56,58,59$ \\
\hline & Annually registration in Ob-Gyns specialty & $19-23,26-31,34,36,37,40,46,52,53,55$ \\
\hline & Duration of Ob-Gyns education & $18-21,30,31,34,40,44,46,48-50,59$ \\
\hline & cost of training Ob-Gyns & $18,46,49,54,59$ \\
\hline & possibility of expansion of ob-gyn residency & $16,18,19,22,26,34,44-46,48,49,52$ \\
\hline \multirow[t]{3}{*}{ residency outflow } & Student dropout rate in the field of Ob-Gyns specialty graduates & $20-23,26,28,30-32,46,53$ \\
\hline & The number of fellowships in Ob-Gyns & $20,31,32,44,48,54$ \\
\hline & The rate of participation of gynecological graduates specialized fields & $20,21,29,37-40,44-46,48,53,54$ \\
\hline \multirow[t]{3}{*}{ Ob-gyn services plasticity(60)/task shifting } & Role of other specialist in Ob-Gyn services & $22,28,32,34,43,45,46,51$ \\
\hline & $\begin{array}{l}\text { contribution of assistants such as midwives In the provision in Ob-Gyn } \\
\text { services }\end{array}$ & $18,22,23,26,28,29,32,33,38,43,45,46,52-54,56$ \\
\hline & The extent of the role of Ob-Gyns & $28,30,38,46,54$ \\
\hline \multirow[t]{5}{*}{ Ob-gyns Full Time Equivalency } & Resident and Fellow Work Hour Restrictions & 46,55 \\
\hline & Productivity of Ob-Gyns & $22,28,30,38,46,52,53,55,56$ \\
\hline & Average Ob-Gyns ' hours of work & $15,18-21,23,25-30,32,34,36,38,46,48,52-54,56$ \\
\hline & The amount of time dedicated to clinical and non-clinical activities & $22,26,28,46,53,55$ \\
\hline & $\begin{array}{l}\text { The amount of Ob-Gyns working in the private and public sector at the same } \\
\text { time }\end{array}$ & 29 \\
\hline \multirow[t]{4}{*}{ Ob-gyns motivations for service delivery } & Job Satisfaction & $18,45,46$ \\
\hline & $\begin{array}{l}\text { Changing practice patterns, including flexible or part-time schedules, } \\
\text { work-life integration }\end{array}$ & $18,22,26-29,38,45,46,52-54$ \\
\hline & medical malpractice premiums & 17 \\
\hline & Type of payment system to physician & 46,52 \\
\hline \multirow{3}{*}{$\begin{array}{l}\text { Structure and System factors Affecting } \\
\text { Supply }\end{array}$} & Modifying care delivery models in Ob-Gyns services & $26,28,30,38,46,53$ \\
\hline & Rate of remote services and telemedicine in Ob-Gyns services & 46 \\
\hline & Staffing patterns & 30,46 \\
\hline
\end{tabular}

administrative, and research activities ${ }^{17,23,25,29,48}$ were among other important determinants of the supply of physicians addressed in recent models.

\section{Discussion}

This systematic review aimed to identify the approaches used to estimate the number of OB-GYNs in different countries, as well as the determinants of supply and demand in this field. The results of analyzing the 45 selected papers showed that most studies have covered both supply and demand sides of OB-GYNs estimations and determined the number of specialists needed based on the difference between the supply and demand. About a quarter of papers, however, have examined either the supply or demand sides. Demand-based calculations were performed by four approaches, the most commonly used of which was utilization-based. On the supply side, except for two papers, the stock and flow method had been used in all papers. Various effective factors (more than 60 factors) had been proposed and employed in different studies to estimate OB-GYNs supply and demand. The wide range of these factors can be indicative of the complexity of HRP in medical fields.

This complexity and incongruity in methods and factors make it difficult to determine the accuracy of the estimates made in various studies. However, examining the models and factors used in previous studies suggests that the new models are moving towards greater completeness and are trying to take into account all aspects of supply, demand, and needs, as well as the use of advanced modeling systems such as simulation and system dynamism. ${ }^{22,25,39,50}$ However, access to complete and accurate data sources has always been one of the limitations of HRP models. That is why various models have focused on a limited number of factors in formulating the estimates and taken into account numerous assumptions, scenarios, and expert opinions to greatly alleviate data problems. ${ }^{16,19-21,27,41,61}$

The study findings indicated that although there is no standardized and comprehensive method for modeling workforces requirement in this field, there are many similarities between medical specialties and health care providers in terms of approaches and factors. Differences in the attitude of HR planners, the amount of data available, and the type of services and diseases covered in each medical specialty have changed the composition of the factors used. ${ }^{28,62-64}$ For example, due to horizontal and vertical overlap with some medical specialties, as well as midwifery and nursing, greater contribution of women to the field of obstetrics and gynecology, and their greater attention to the work-life balance, determining the available active workforce (supply) in this field requires greater focus and precision. Inattention to these factors leads to unrealistic estimation and creates a surplus or shortage of OBGYNs.

As the results showed, various methods and models have been designed and implemented to estimate OB-GYNs. The ever-increasing changes in social, political, cultural, economic, and technological conditions have altered the pattern of diseases, social needs and demands for services, as well as the ways and means of providing these services. As mentioned in many studies, ${ }^{26,36,52}$ physician workforce forecasting is not a precise and stringent science. Since the factors affecting supply and demand change constantly, they should be continually monitored to address assumptions, scenarios, and policy changes to affect the real requirements.

Despite the valuable results of the current systematic review, this study had some limitations like other studies. Restricted knowledge on other languages and the choice of merely English or Farsi studies are 
likely to exclude some of the knowledge produced in other languages. Additionally, despite the selection of a sophisticated search strategy and searching a large number of databases, there may still exist a knowledge gap in this area due to the high volume of gray literature in the field and unpublished organizational reports, especially in developing and underdeveloped countries.

\section{Conclusion}

This study was conducted to investigate the factors affecting the determinants of the OB-GYNs supply and demand. The result showed that different models with a set of heterogeneous factors have been used to estimate the OB-GYNs supply and demand. The data showed more commonly-used factors produced more accurate and complete estimates. Given the importance of proper estimation of the number of required obstetricians and gynecologists and other specialties, HRH planners and policymakers should pay more attention to the complexities and different dimensions of this issue.

\section{Financial support and sponsorship}

The study was supported by Iran University of Medical Sciences, Tehran, Iran.

\section{Declaration of competing interest}

There are no conflicts of interest.

\section{Acknowledgment}

This article is a part of $\mathrm{PhD}$ thesis supported by Iran University of Medical Sciences with grant number of IUMS/SHMIS 1394/32. Researchers are grateful to thank all the colleagues especially managers and personnel for their efforts.

\section{References}

1. World Health Organization. Health workforce and labor market dynamics in OECD high-income countries: a synthesis of recent analyses and simulations of future supply and requirements. Hum Resour Health Observer. 2017;20.

2. Campbell J, Buchan J, Cometto G, et al. Human resources for health and universa health coverage: fostering equity and effective coverage. Bull World Health Organ. 2013;91:853-863

3. Lagrew Jr DC, Jenkins TR. The future of obstetrics/gynecology in 2020: a clearer vision. Why is change needed? (2014). Am J Obstet Gynecol. 2014;211(5):470-474 1.

4. Alston MJ, Wagner SA, Winkel A, Allshouse AA, StephensonFamy A. Obstetricians and gynecologists of the future: a survey of medical students applying to residency Obstet Gynecol. 2017:130:1S-7S.

5. Pulcrano M, Evans SR, Sosin M. Quality of life and burnout rates across surgical specialties: a systematic review. JAMA surgery. 2016;151(10):970-978.

6. Wang P-H, Sheu B-C, Yeh J-Y. The Sunset Industry: obstetrics and gynecology concerns about the shortage of obstetricians and gynecologists. Am J Obstet Gynecol. 2009;201(4):e12

7. Lopes MA, Almeida Á.S, Almada-Lobo B. Handling healthcare workforce planning with care: where do we stand? Hum Resour Health. 2015:13(1):1-19.

8. Pearse WH. Is there a surplus of obstetrician-gynecologists? Am J Obstet Gynecol. 1983;147(2):133-137

9. Kroezen M, Van Hoegaerden M, Batenburg R. The joint action on health workforce planning and forecasting: results of a european programme to improve health workforce policies. Health Policy. 2018;122(2):87-93.

10. Batenburg R. Health workforce planning in Europe: creating learning country clusters. Health Policy. 2015;119(12):1537-1544.

11. Ono T, Lafortune G, Schoenstein M. Health Workforce Planning in OECD Countries. 2013; 2013.

12. Moher D, Liberati A, Tetzlaff J, Altman DG. Preferred reporting items for systematic reviews and meta-analyses: the PRISMA statement. Ann Intern Med. 2009;151(4):264-269

13. Public Health Resource Unit. The Critical Skills Appraisal Programme: Making Sense of Evidence. England: Public Health Resource Unit; 2006 Retrieved from http://www. casp-uk.net/.

14. Masnick K, McDonnell G. A model linking clinical workforce skill mix planning to health and health care dynamics. Hum Resour Health. 2010;8(1):11

15. Alaedini f Estimation of the Number of 12 Clinical Trials Required for Country 2025. Ministry of Health and Medical Education, Educational deputy,Health Human
Resources Training Planning Working Group; 2015 ([In persian]).

16. Alshishtawy M. Medical specialties in Oman: scaling up through national action. Oman Med J. 2009;24(4):279.

17. Anderson BL, Hale RW, Salsberg E, Schulkin J. Outlook for the future of the obstetrician-gynecologist workforce. Am J Obstet Gynecol. 2008;199(1):88 e1-. e8.

18. Australian Medical Workforce Advisory Committee. The Obstetrics and Gynaecology Workforce in Australia: Supply and Requirements. 1997-2008; 1997-2008 AMWA 1998.

19. Australian Medical Workforce Advisory Committee. The Specialits Obestetrics and Gynecology Workforce in australia an Update. 2013; 2013 2004. 2003.

20. Bayat m, Shokri a, salehizalani gh. Projection of Specialists Sector Workforce Requirement: Vision 2025. Center for Health Human Resources Research and Studies: Ministry of Health and Medical Education; 2017 ([In Persian]).

21. Behan J, Condon N, Milicevic I, Shally C. A Quantitative Tool for Workforce Planning in Healthcare: Example Simulations. Report by the Skills and Labour Market Research Unit (FÁS) on Behalf of the Expert Group on Future Skills Needs Dublin. FÁS; 2009.

22. CfW Intelligence. Securing the Future Workforce Supply- Obstetrics and GynaecologY Socktake. Centre for Workforce Intelligence London; 2015.

23. Chilvers R. Planning Framework for Human Resources for Health for Maternal and Newborn Care PhD thesis London School of Hygiene \& Tropical Medicine; 2014.

24. Dall TM, Chakrabarti R, Storm MV, Elwell EC, Rayburn WF. Estimated demand for women's health services by 2020. J Women's Health. 2013;22(7):643-648.

25. Dall T. The Complexities of Physician Supply and Demand: Projections from 2016 to 2030. IHS Markit Limited; 2018.

26. Health Workforce Australia. Australia's Future Health Workforce - Obstetrics and Gynaecology 2018

27. Texas Department of State Health Services. Texas Projections of Supply and Demand for Primary Care Physicians and Psychiatrists. 2018; 2018:2017-2030.

28. Council on Graduate Medical Education. Evaluation of Specialty Physician Workforce Methodologies. U.S. Department of Health and Human services, Health Resources and Services Administration; 2000.

29. Eguchi N. Do we have enough obstetricians? - a survey by the Japan medical association in 15 countries. Japan Med Assoc J. 2009;52(3):150-157.

30. Elliott Rose A. Centering Women and Newborns in Health Human Resources Planning: A Needs-Based Approach to Primary Maternity Health Care in Nova Scotia [PhD Thesis]. Halifax, Nova Scotia: Dalhousie University; 2015.

31. Fraher EP, Knapton A, Sheldon GF, Meyer A, Ricketts TC. Projecting surgeon supply using a dynamic model. Ann Surg. 2013;257(5):867-872.

32. Fraher EKA, Holmes GM. The Future Supply and Demand of Physicians in the Charlotte Region and Rest of North Carolina, 2017-2035. Cecil G. Sheps Center for Health Services Research. The University of North Carolina at Chapel Hill; 2016.

33. Anastasia Gunawan JP, Tabor G. Northern Nevada Obstetrics and Gynecology Need Assessment. Office of Statewide Initiatives University of Nevada, Reno School of Medicine; 2017.

34. Australia Health Workforce. Health Workforce 2025-Volume 3-Medical Specialties 2012.

35. Ide H, Yasunaga H, Kodama T, Koike S, Taketani Y, Imamura T. The dynamics of obstetricians and gynecologists in Japan: a retrospective cohort model using the nationwide survey of physicians data. J Obstet Gynaecol Res. 2009;35(4):761-766.

36. IHS Global Inc. Florida Statewide and Regional Physician Workforce Analysis: Estimating Current and Forecasting Future Supply and Demand. Prepared for the Safety Net Hospital Alliance of Florida; 2015.

37. Ishikawa T, Ohba H, Yokooka Y, Nakamura K, Ogasawara K. Forecasting the absolute and relative shortage of physicians in Japan using a system dynamics model approach. Hum Resour Health. 2013;11(1):41.

38. Jacoby I, Meyer GS, Haffner W, Cheng EY, Potter AL, Pearse WH. Modeling the future workforce of obstetrics and gynecology. Obstet Gynecol. 1998;92(3):450-456.

39. National Center for Health Workforce Analysis. National and Regional Projections of Supply and Demand for Women's Health Service Providers. U.S. Department of Health and Human Services Health Resources and Services Administration Bureau of Health Workforce; 2013-2025 2016.

40. Fujitsu Consulting Inc. Setting a New Direction for Planning. Canada: the New Brunswick Physician Workforce; 2003.

41. Nigenda G, Muños JA. Projections of specialist physicians in Mexico: a key element in planning human resources for health. Hum Resour Health. 2015;13(1):79.

42. Noori Hekmat S, Hashemi H, Haghdoost A, et al. Specialized and geographic distribution of specialists in Iran in 2016 and its estimates in 2026. Iran J Epidemiol 2018;13:122-132.

43. Pearse WH, Mendenhall RC, Radecki SE, Shipp DA, Fielden JG. Manpower for obstetrics-gynecology: III. Contributions to total female medical care. Am J Obstet Gynecol. 1982;144(3):332-336.

44. Pearse WH, Gant NF, Hagner AP. Workforce projections for subspecialists in obstetrics and gynecology. Obstet Gynecol. 2000;95(2):312-314.

45. Rayburn WF, Tracy EE. Changes in the practice of obstetrics and gynecology. Obstet Gynecol Surv. 2016;71(1):43-50.

46. Rayburn WF. The Obstetrician-Gynecologist Workforce in the United States. Washington DC: American Congress of Obstetricians and Gynecologists; 2017.

47. Ronsmans C, Campbell OMR, McDermott J, Koblinsky M. Questioning the indicators of need for obstetric care. Bull World Health Organ. 2002;80:317-324.

48. Royal College of Obstetricians and Gynaecologists. The Future Workforce in Obstetrics and Gynaecology England and Wales 2009; 2009 Full Report.

49. Satiani B, Williams T, Landon M, Ellison C, Gabbe S. A critical deficit of OBGYN surgeons in the US by 2030. Surg Sci. 2011;2(02):95.

50. Senese F, Tubertini P, Mazzocchetti A, Lodi A, Ruozi C, Grilli R. Forecasting future needs and optimal allocation of medical residency positions: the Emilia-Romagna Region case study. Hum Resour Health. 2015;13(1):7.

51. Shelton RD. Analysis of the Demand for Primary Care, Pediatric, and OB-GYN Physicians 
and of the Cost to Establish a Primary Care Physician Practice for Logan County. Oklahoma; 2001.

52. Singh D, Lalani H, Kralj B, et al. Ontario Population Needs-Based Physician Simulation Model. Toronto: Ontario Ministry of Health and Long-Term Care; 2010.

53. Social Sector Metrics Inc, Health Intelligence Inc. Physician Resource Planning, A Recommended Model and Implementation Framework. submitted to the Nova Scotia Department of Health and Wellness; 2012.

54. Stonehocker J, Muruthi J, Rayburn WF. Is there a shortage of obstetrician-gynecologists? Obstet.Gynecol. Clin. 2017;44(1):121-132

55. The Center for Health Workforce Studies. Michigan Physician Supply and Demand through 2020. NY: University at Albany, State University of New York, School of Public Health: State University of New York Renseelaer; 2006

56. Health Resources and Services Administration. The Physician Workforce: Projections and Research into Current Issues Affecting Supply and Demand. Rockville, MD: US Dept of Health and Human Services; 2008.

57. Verhulst L, Forrest CB, McFadden M. To count heads or to count services? Comparing population-to-physician methods with utilization-based methods for physician workforce planning: a case study in a remote rural administrative region of British Columbia. Healthc Policy. 2007;2(4):e178.

58. Wallace AH, Havrilesky LJ, Valea FA, Barnett JC, Berchuck A, Myers ER. Projecting the need for gynecologic oncologists for the next 40 years. Obstet Gynecol. 2010;116(6):1366-1372

59. Williams Jr TE, Satiani B, Thomas A, Ellison EC. The impending shortage and the estimated cost of training the future surgical workforce. Ann Surg. 2009;250(4):590-597.

60. Holmes GM, Morrison M, Pathman DE, Fraher E. The contribution of "plasticity" to modeling how a community's need for health care services can be met by different configurations of physicians. Acad Med. 2013;88(12):1877-1882.

61. Fellows J, Edwards M. User Guidelines on Qualitative Methods in Health Workforce Planning and Forecasting. London: Centre for Workforce Intelligence; 2014.

62. Malgieri A, Michelutti P, Hoegaerden M. Handbook on Health Workforce Planning Methodologies across EU Countries. Bratislava: Ministry of Health of the Slovak Republic; 2015.

63. Unger J, Putrik P, Buttgereit F, et al. Workforce requirements in rheumatology: a systematic literature review informing the development of a workforce prediction risk of bias tool and the EULAR points to consider. RMD open. 2018;4(2):e000756.

64. MacKenzie A, Murphy GT, Audas R. A dynamic, multi-professional, needs-based simulation model to inform human resources for health planning. Hum Resour Health. 2019;17(1):42. 